\title{
Numerical study of the response of the ocean to a northerly wind jet in the equatorial Eastern Pacific
}

\author{
K. Mosquera \\ Instituto Geofísico del Perú, Lima, Perú \\ Received: 16 June 2007 - Revised: 3 September 2007 - Accepted: 3 September 2007 - Published: 10 April 2008
}

\begin{abstract}
The response of the equatorial and South American coastal ocean circulation to the anomalous March 2002 wind jet extending from the Gulf of Panama to $6^{\circ} \mathrm{S}$ is studied in a linear ocean model. Two experiments were performed: one without continental boundaries and the other with an eastern boundary at $81^{\circ} \mathrm{W}$, representing the American continent. The spatial and temporal structure of the imposed wind anomaly, represented with idealized mathematical functions, is similar to that of the real jet. The duration of the wind jet was six days where the maximum intensity occurred at the third day. The results of the experiments indicate that the wind-jet anomaly over the Gulf of Panama is another source of ocean waves that influence the western coast of South America in the form of coastal Kelvin waves (CKW).
\end{abstract}

\section{Introduction}

January through March of a typical year is characterized by sea-level pressure differences of $2-4 \mathrm{mb}$ betweeen the Atlantic and Pacific sides of Central America, and resultant strong atmospheric jets across the isthmuses of Tehuantepeq, Papagayo, and Panama (Chelton et al., 2002). Fluctuations in the strength of the jets affect the ocean temperature (Stumpf, 1975) and chlorophyll (Rodriguez-Rubio and Stuardo, 2002) over the Gulf of Panama, and the ocean circulation (McCreary et al., 1989; Trasviña et al., 1995) in the Gulf of Papagayo and Tehuantepeq.

In 2002 the equatorial Pacific ocean conditions during these calendar months were very unusual. McPhaden (2004) documented strong westerly winds in the western Pacific in December 2001, which excited an intraseasonal equatorial Kelvin wave that increased the depth of the thermocline by 20-30 $\mathrm{m}$ and warmed the surface waters to the east of the

Correspondence to: K. Mosquera

(kobi@chavin.igp.gob.pe) dateline. This wave reached the eastern Pacific at the end of February and warmed the sea water along the coast of Peru. This ocean process and westerly winds near the coast have been used to explain strong rainfall over Piura, northwestern Peru (around $5^{\circ} \mathrm{S}$ ), in March and April (Takahashi, 2004).

In March 2002, the Gulf of Panama wind jet crossed the equator between the Ecuador coast and the Galapagos $\left(90^{\circ} \mathrm{W}\right)$, penetrating as far south as $6^{\circ} \mathrm{S}$ between $88^{\circ} \mathrm{W}$ and $94^{\circ} \mathrm{W}$ (Fig. 1). A possible interpretation of this unusual occurrence is that it was a consequence of above normal sea surface temperatures inducing below normal pressures in this region (Lindzen and Nigam, 1987).

The present work documents an oceanic model response to this atmospheric anomaly, including how the sea level, along the coast is perturbed The following sections describe the numerical model, the results of the simulations, and the conclusions.

\section{The model}

The following subsections describe the wind and ocean models employed in this analysis.

\subsection{The wind model}

The March 2002 wind anomaly event is characterized in terms of exponential, sine and cosine functions. For this, we consider that the wind burst starts at $9^{\circ} \mathrm{N}$ and $85^{\circ} \mathrm{W}$ and increases its intensity for three days, reaching $8^{\circ} \mathrm{S}$ in the third day, and then decreases to zero in the following three days.

The above description is modeled on a sphere $(\theta$ is latitude and $\phi$ is longitude) with the following equations:

$\tau^{\phi}=0$

$\tau^{\theta}=-8 c_{D} \rho \Phi(\phi) \Theta(\theta) T(t)$

Published by Copernicus Publications on behalf of the European Geosciences Union. 


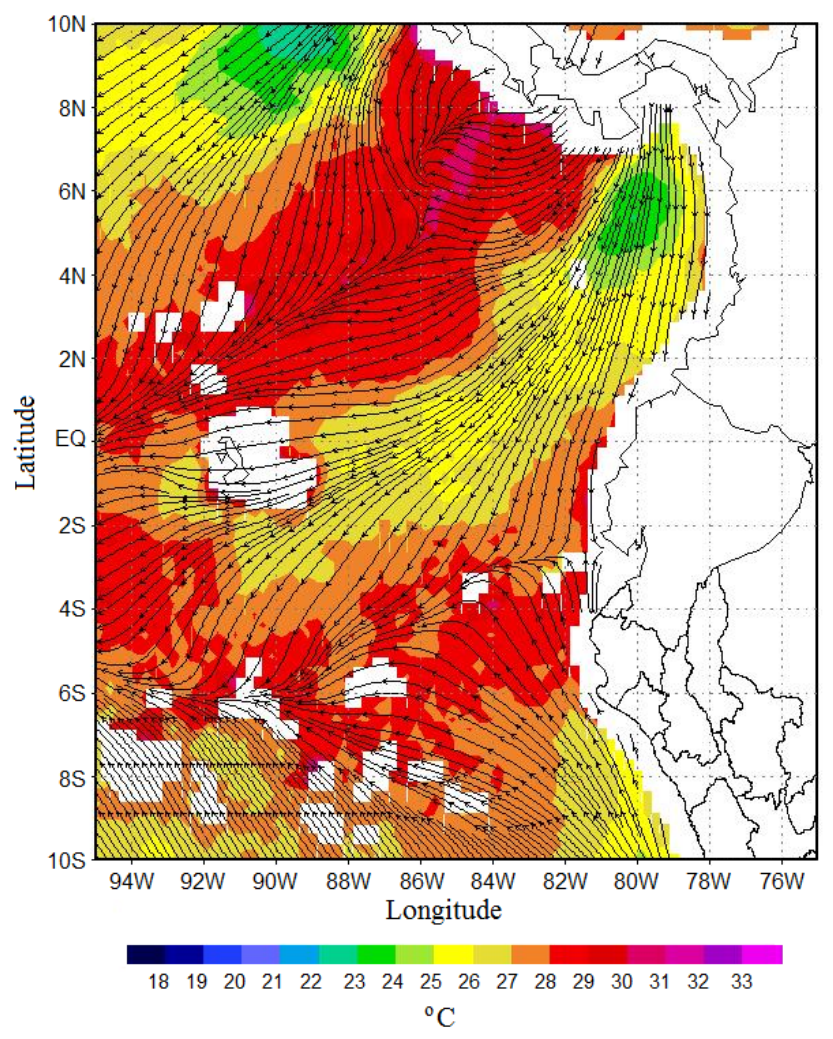

Fig. 1. Sea surface temperature (from TMI) and streamlines (calculated from QSCAT data) on 10 March 2002.

where $c_{D}$ is the drag coefficient and $\rho$ represents the density of the air. In this particular simulation, according to McPhaden (2004), we use the values of $1.2 \times 10^{-3}$ and $1.2 \mathrm{~kg} \mathrm{~m}^{-3}$ for $c_{D}$ and $\rho$, respectively. The functions: $\Phi(\phi)$, $\Theta(\theta)$ and $T(t)$ are represented by the following statements:

$$
\begin{array}{cr}
\Theta(\theta)=\cos \left(\frac{\pi\left(\theta-10^{\circ}\right)}{2\left(20^{\circ}\right)}\right) & -10^{\circ} \leq \theta \leq 10^{\circ} \\
\Phi(\phi)=e^{-\frac{\left(\phi+85^{\circ}\right)^{2}}{8^{\circ}}} & -90^{\circ} \leq \phi \leq-80^{\circ} \\
T(t)=\sin \left(\frac{\pi(t-1)}{287}\right) & 1 \leq t \leq 288
\end{array}
$$

All of these equations are represented in the Fig. 2, where we can see the spatial and temporal structure of the theoretical wind jet.

\subsection{The ocean model}

The ocean model is linear, following McCreary et al. (1989), with two differences: (1) there is no diffusion parameter and (2) the model is in spherical coordinates. Essentially the model, is a $11 / 2$ layer model with an active upper layer, with $\rho_{1}$ as a density, over a motionless layer with density $\rho_{2}$.

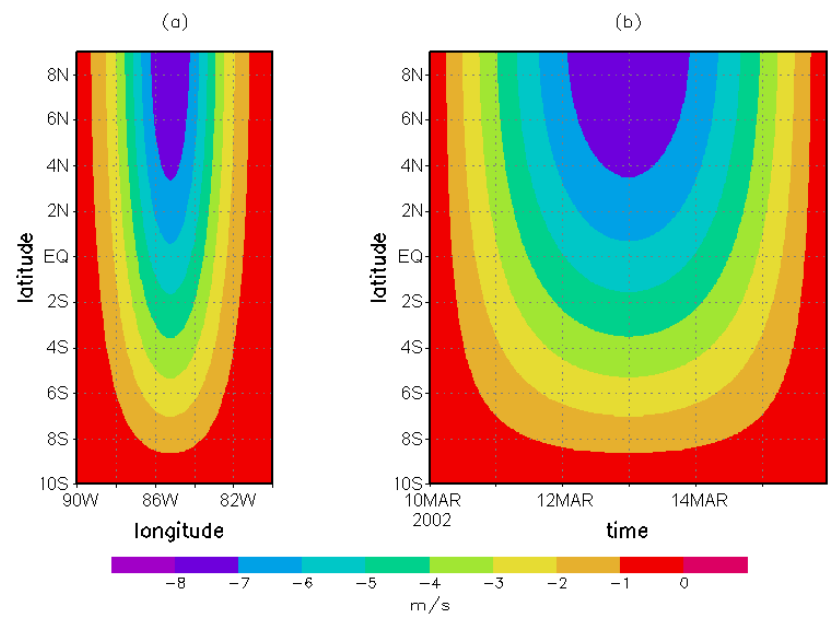

Fig. 2. Characteristics of the Wind model: (a) spatial and (b) temporal structure.

The equations that describe the idealized ocean are:

$$
\begin{aligned}
& \frac{\partial u}{\partial t}-2 \Omega v \sin \theta=-\frac{g}{R \cos \theta} \frac{\partial \eta}{\partial \phi}+\frac{\tau^{\phi}}{H} \\
& \frac{\partial v}{\partial t}+2 \Omega u \sin \theta=-\frac{g}{R} \frac{\partial \eta}{\partial \theta}+\frac{\tau^{\theta}}{H} \\
& \frac{\partial \eta}{\partial t}=-\frac{H g^{\prime}}{g}\left(\frac{1}{R \cos \theta} \frac{\partial u}{\partial \phi}+\frac{1}{R} \frac{\partial v}{\partial \theta}\right)
\end{aligned}
$$

where $\phi$ and $\theta$ are the longitude and latitud, respectively, $R$ the radius of the Earth, $u$ and $v$ are the velocities of the zonal and meridional components, respectively. $\eta$ is the sea level, $H$ the thickness of the upper layer, and $2 \Omega \sin \theta$ the Coriolis parameter. Additionally, $\tau^{\phi}$ and $\tau^{\theta}$ are the zonal and meridional component of the wind stress. Finally, $g^{\prime}=\left[\left(\rho_{2}-\rho_{1}\right) /\left(\rho_{2}\right)\right] g$ is the reduced gravity and $g$ the gravity of the earth.

The values for some parameters are: $H=100 \mathrm{~m}$, $g^{\prime}=0.0196 \mathrm{~m} / \mathrm{s}^{2}$ and $R=6371 \times 10^{3} \mathrm{~m}$.

For the numerical integration we use the C-Arakawa grid, recommended by Mesinger and Arakawa (1976). The leapfrog scheme (Krishnamurti et al., 1998) is employed for time integration and for the spatial differencing we use the centered scheme. Even though the wind jet has a small domain, compared with the entire globe, we computed for $40^{\circ} \mathrm{S}$ to $40^{\circ} \mathrm{N}$ and $0^{\circ}$ to $360^{\circ}$, with $\Delta x=\Delta y=0.25^{\circ}$, to avoid reflected waves.

\section{Results}

\subsection{Without boundary}

The simulation shows two types of disturbances: one disturbance is around the wind jet $\left(0^{\circ}\right.$ to $\left.10^{\circ} \mathrm{N}\right)$, and it moves 


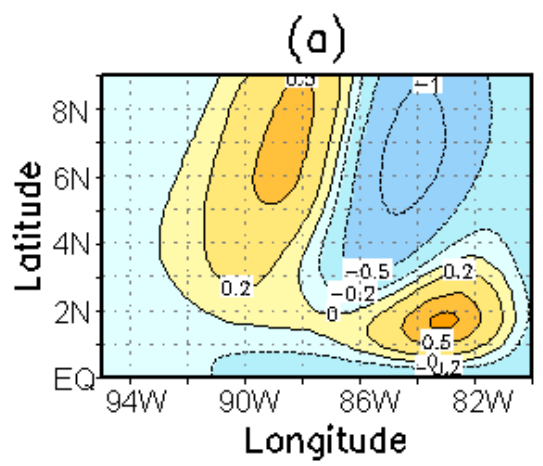

(c)

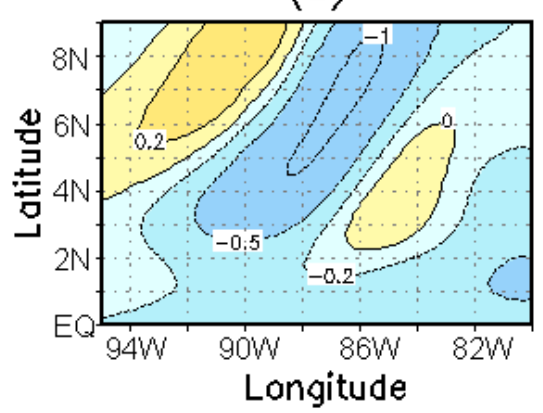

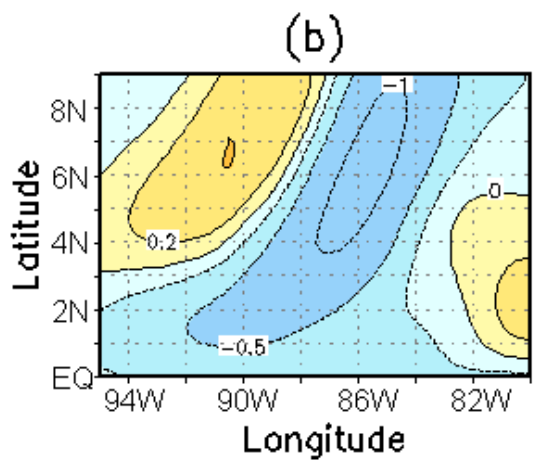

(d)

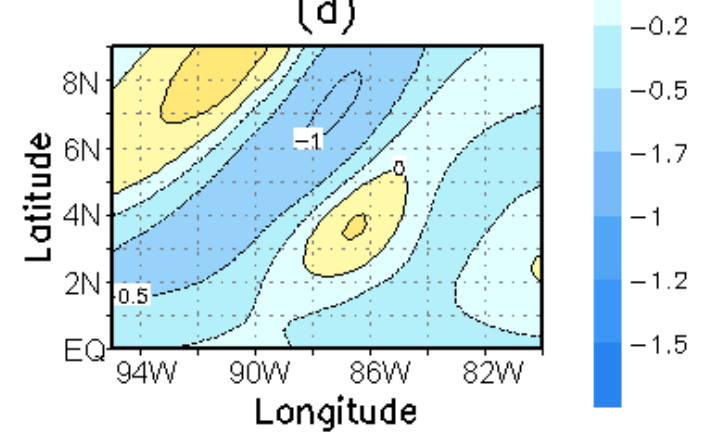

Fig. 3. Perturbation of the sea level in 4 different dates: (a) 25 March (b) 10 April (c) 25 April and (d) 10 May. These waves are moving to the west as a packet of Rossby waves due to the rotation of the earth.

slowly towards the west, like a packet of Rossby waves (McCreary et al., 1989),. These waves exhibit a southern edge that moves faster than the northern edge, due to the variable Coriolis parameter (Fig. 3). The second disturbance has the form of a mixed Rossby - gravity (MRG) wave because its displacement is to the east and, with the time, it has a dispersive behaviour (Fig. 4).

\subsection{With a boundary}

In this experiment a north-south boundary placed at $81^{\circ} \mathrm{W}$ is used to represent the coast. The results show, after 5 days, a small pair of coastal Kelvin waves (CKW) with $1 \mathrm{~m}$ as an absolute value in the sea level moving to the north and to the south, increasing and decreasing the sea level, respectively. After nine days, several more CKW perturb the ocean, but the upwelling wave is towards the south and it is downwelling towards north. After 15 days, several more CKW are present near the boundary with the same configuration as the first waves (upwelling perturbation towards north and downwelling towards south). Finally, a small pair of CKW appears after 26 days. The velocity of the perturbations, moving to the poles, are approximatelly $1.41 \mathrm{~m} / \mathrm{s}$ (see Fig. 5).

Using the results of the first simulation we can see that these CKW, which always move in opposite direction, are consequences of the impact of the MRG in the western boundary $\left(81^{\circ} \mathrm{W}\right)$ as part of the normal dispersion of the MRG.

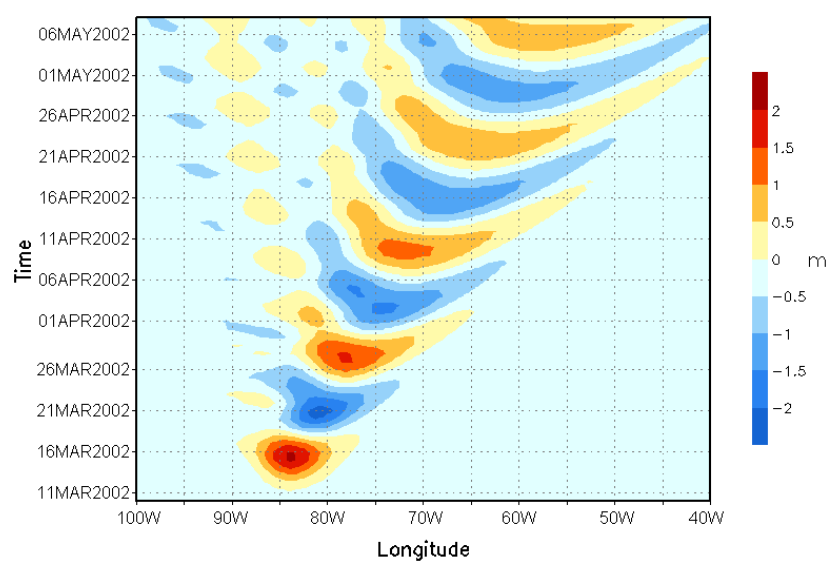

Fig. 4. Perturbation of the sea level along $2.5^{\circ} \mathrm{S}$, this wave has the form of the MRG.

\section{Conclusions}

Intraseasonal variability of the sea level along the American western boundary is associated with equatorial Kelvin waves that are produced by disturbances in the seasonal winds in the western and central equatorial Pacific (Enfield et al., 1987; Johnson and O'Brien, 1990). The equatorial perturbations reach the eastern Pacific and move north and south along the American coast. In this work we demonstrated that anoma- 


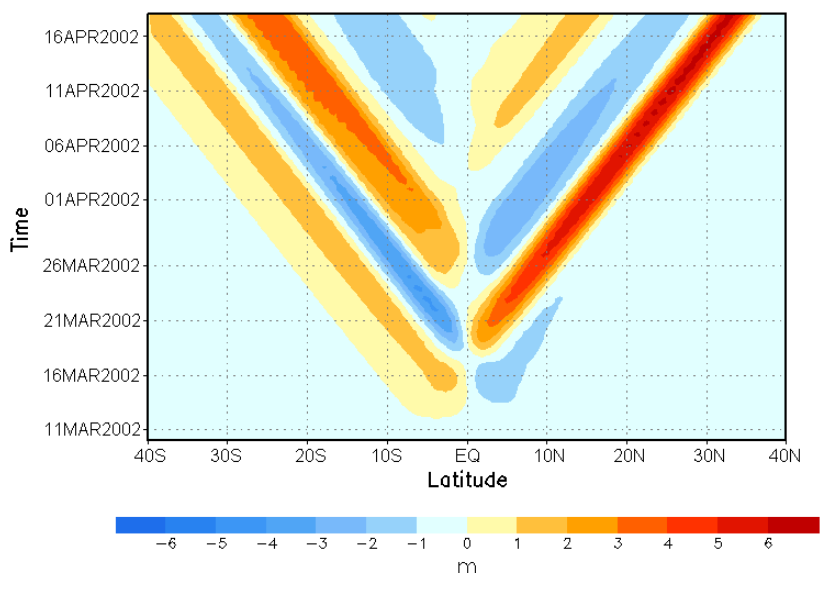

Fig. 5. Coastal Kelvin Waves along a boundary on $81^{\circ} \mathrm{W}$.

lous northerly wind jet from the Gulf of Panama is another form of ocean perturbation that influences the variability of sea level in the eastern Pacific. This mechanism starts when an anomalous wind jet creates MRG that, as a natural behavior, moves to the east and impacts the easterm boundary transforming its energy to pairs of CKW (upwelling and downwelling) with a velocity of $1.41 \mathrm{~m} / \mathrm{s}$. Another important conclusion is the demonstration of the existence of a packect of Rossby waves in the Gulf of Panama after a wind burst. The explanation of this is similar to that of McCreary (1989) for the Tehuantepeq wind-forcing simulation where the waves move to the west and deform due to the Coriolis paramter. In our experiment the deformation of this packet is faster than in McCreary's experiment because of the proximity to the equator.

Acknowledgements. This study is part of the master thesis of K. Mosquera. The author thanks K. Takahashi and T. Mitchell of the University of Washington for their useful comments and suggestions that improved this manuscript.

Edited by: P. Fabian

Reviewed by: two anonymous referees

\section{References}

Chelton, D. B., Freilich, M. H., and Esbensen, S. K.: Satellite Observations of the Wind Jets off the Pacific Coast of Central America. Part I: Case Studies and Statistical Characteristics, Mon. Wea. Rev., 128, 1993-2018, 2000.

Enfield, D.: The Intraseasonal Oscillation in Eastern Pacific Sea Level, How is it forced?, J. Phys. Ocean., 17, 1860-1876, 1987.

Johnson, M. A. and O'brien, J. J.: The role of coastal Kelvin waves on the northeast Pacific Ocean, J. Mar. Syst., 1, 29-38, 1990.

Krishnamurti, T. H., Bedi, H. S., and Hardiker,V. M.: An Introduction to Global Spectral Modeling, Oxford University Press, 253 pp., 1998.

Lindzen, R. S. and Nigam, S.: On the role of sea surface temperature gradients in forcing low level winds and convergence in the tropics, J. Atmos. Sci., 44, 2440-2458, 1987.

McCreary, J. P., Hu, H. S., and Enfield, D. B.: The response of the coastal ocean to strong off shore winds: With application to circulations in the Gulfs of Tehuantepec and Papagayo, J. Mar. Res., 47, 82-109, 1989.

McPhaden, M. J.: Evolution of the 2002-03 El Niño, B. Am. Meteorol. Soc., 85, 677-695, 2004.

Mesinger, F. and Arakawa, A.: Numerical methods used in atmospheric models, GARP Publ. Ser., 17(I), 64 pp., 1976.

Rodriguez-Rubio, E. and Stuardo J.: Variability of Photosynthetic pigments in the Colombian Pacific Ocean and its relationship with the wind field using ADEOS-I data, Proc. Indian Acad. Sci. (Earth Planet. Sci.), 111, 3, 227-236, September 2002.

Stumpf, H. G.: Satellite Detection of Upwelling in the Gulf of Panama, Mexico, J. Phys. Oceanogr., 5, 383-388, 1975

Takahashi, K. :The atmospheric circulation associated with extreme rainfall events in Piura, Peru, during the 1997-98 and 2002 El Niño events, Ann. Geophys., 22, 3917-3926, 2004, http://www.ann-geophys.net/22/3917/2004/.

Trasviña, A., Barton, E. D., Brown, J., Velez, H. S., Kosro, P. M., and Smith, R. L.: Offshore wind forcing in the gulf of tehuantepec, Mexico: The asymmetric circulation, J. Geophys. Res., 100(C10), 20 649-20663, 1995. 